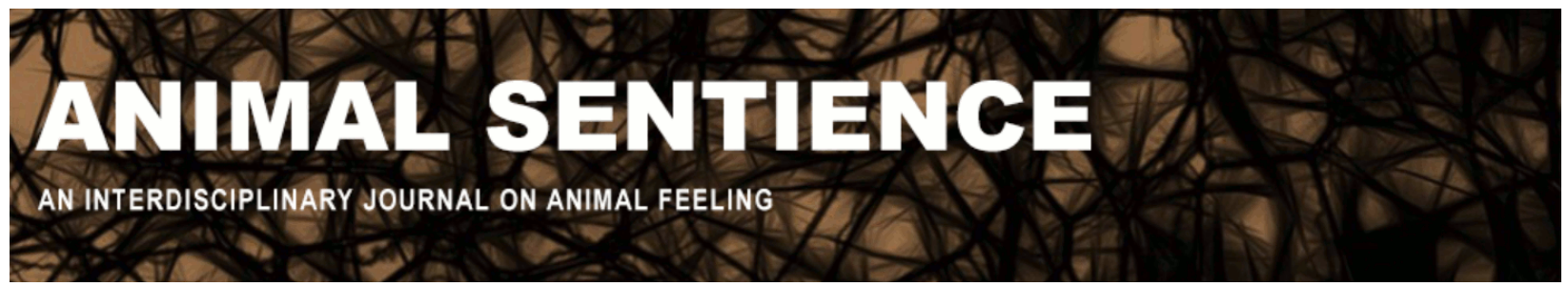

Mikhalevich, Irina (2018) Animal suicide: An account worth giving?. Animal Sentience 20(19)

DOI: $10.51291 / 2377-7478.1316$

Date of submission: 2018-03-08

Date of acceptance: 2018-04-06

(c)

This article has appeared in the journal Animal

Sentience, a peer-reviewed journal on animal

cognition and feeling. It has been made open access,

free for all, by WellBeing International and deposited

in the WBI Studies Repository. For more information,

please contact

wbisr-info@wellbeingintl.org.

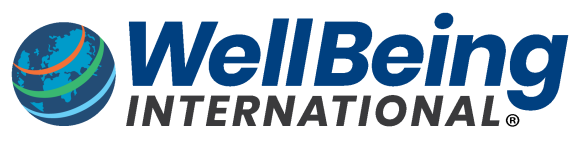

SOLUTIONS FOR PEOPLE, ANIMALS AND ENVIRONMENT 


\title{
Animal suicide: An account worth giving?
}

Commentary on Peña-Guzmán on Animal Suicide

\author{
Irina Mikhalevich \\ Department of Philosophy \\ Rochester Institute of Technology
}

\begin{abstract}
Peña-Guzmán (2017) argues that empirical evidence and evolutionary theory compel us to treat the phenomenon of suicide as continuous in the animal kingdom. He defends a "continuist" account in which suicide is a multiply-realizable phenomenon characterized by selfinjurious and self-annihilative behaviors. This view is problematic for several reasons. First, it appears to mischaracterize the Darwinian view that mind is continuous in nature. Second, by focusing only on surface-level features of behavior, it groups causally and etiologically disparate phenomena under a single conceptual umbrella, thereby reducing the account's explanatory power. Third, it obscures existing analyses of suicide in biomedical ethics and animal welfare literatures. A more promising naturalistic approach might seek a theoretical understanding of the social/ecological circumstances that drive humans and perhaps other animals to self-destruction.
\end{abstract}

Irina Mikhalevich is Assistant Professor of Philosophy at the Rochester Institute of Technology. Her research examines conceptual and methodological problems in comparative (animal) cognition science and their implications for the treatment of nonhuman animals. https://www.irinamikhalevich.com/

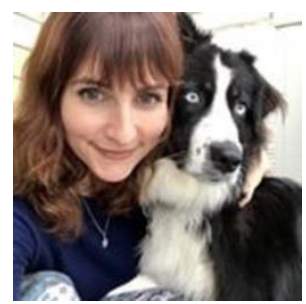

Peña-Guzmán (2017) argues that the empirical evidence of sophisticated animal cognition and Darwinian evolutionary theory compels us to treat the phenomenon of suicide as continuous in the animal kingdom - one that may be found even among invertebrates. After making a compelling case that some animals may have the mental wherewithal to make an informed decision about ending their own lives, Peña-Guzmán proposes a "continuist" view, which avoids any reference to mental states and instead defines suicide in exclusively behavioral terms. Suicide, he maintains, is a multiply-realizable phenomenon characterized by self-injurious and selfannihilative behaviors, admitting of many different proximate psychological causes and evolutionary-developmental histories. He writes:

At one end of this spectrum, we find some of the most sophisticated acts of self-annihilation of cognitively complex animals, humans included; at the other end, we find more basic forms of selfinjury and self-destruction, such as the self-sting of the scorpion.

The continuist view thus classifies both the fully-informed and rational decision of a terminally ill patient to take her own life and the self-sting of a scorpion as "suicide," albeit produced by different psychological states and evolutionary and developmental histories in each case. Peña- 
Guzmán is right that the possibility that some nonhuman animals can commit suicide cannot be ruled out $a$ priori and that the phenomenon deserves a naturalistic, rather than a theological or metaphysical, gloss. However, the "continuist" approach is problematic for several reasons.

First, the continuist thesis is presented as a naturalistic alternative to untenable metaphysical and theological approaches to suicide. Its name appears to be an homage to the thesis of mental evolution, which rejects the anthropocentric view that only humans have minds. However, Peña-Guzmán appears to misconstrue the mental continuity thesis as holding that either a mental trait is uniquely human or else it is widely distributed in nature; this misinterpretation appears to operate behind the continuist approach, which holds that suicide is a widely distributed trait, present to some degree even among scorpions. However, evolutionary continuity holds only that the same principles that apply to the rest of the biological world also apply to human beings, and mental continuity applies this principle to the mind. ${ }^{1}$ Thus, we should expect similarity ("continuity") when we have good reason to expect that the psychology of a given animal lineage evolved in response to similar selection pressures (through convergent evolution), due to shared evolutionary history (through homology), or because it was subject to similar developmental constraints. Instead of adopting this line of reasoning, the continuist view simply extends the description to all animals who engage in self-injurious and self-annihilative behaviors, irrespective of their histories of selection or development. This strategy has consequences for the explanatory power of the continuist view, which brings me to my next point of criticism.

According to Peña-Guzmán, the continuist approach has superior explanatory power relative to the intention-based alternatives in part because it correctly classifies the selfannihilative acts of children and the cognitively impaired as "suicide" despite their inability to grasp the significance of the act and to form the right sort of intentions. However, an intentionbased account can accommodate self-annihilation by cognitively limited people by simply relaxing the requirements on what counts as the proper intention. It may, furthermore, be better able to explain why some self-annihilative acts by cognitively sophisticated nonhuman animals should be regarded as "suicide."

More problematically, by extending the description to a broad class of animals without offering a deep theoretical structure to connect them, the continuist account undercuts its own explanatory power. By disregarding the evolutionary history and ecological and social significance of self-annihilative behaviors, it produces a heterogeneous class that groups adaptive behaviors with those that are either maladaptive or stochastic. Adaptive self-annihilative examples include carpenter ants that explode in battle, covering their enemies in toxic goo (Davidson et al. 2012). Meanwhile, the scorpion self-sting may have been the accidental result of erratic contortions and is unlikely to have been the cause of death, as many scorpions are immune to their own venom (Legros et al. 1998). These behavioral types have radically different causal histories and ecological significance, and, by ignoring these, the continuist approach is unable to explain why we should expect to see similar forms of suicidal behaviors emerging in certain environments. Indeed, the continuist approach could make a stronger case for the multiple-realizability of suicide by offering a conceptual framework that might explain how animals as different as, for example, humans and ants could produce strikingly similar forms of suicidal behaviors (e.g., suicide bombing) under

\footnotetext{
${ }^{1}$ See also Preti (2018) for a similar objection.
} 
specific ecological conditions (e.g., "war") despite using different proximate mechanisms (e.g., a system of culturally mediated beliefs among humans and a chemical signaling system among eusocial carpenter ants).

Put slightly differently, the continuist approach fails at the task of trait-delineation by classifying many causally unrelated but superficially similar actions under a single heading. Traitdelineation becomes more challenging when the subject is a complex socio-behavioral trait (or alleged trait) such as altruism, punishment, rape, and suicide. Consider, for example, the attempt to naturalize rape as an adaptive reproductive strategy of low-quality males (Thornhill and Palmer 2000). This account has been criticized for (among other things) failing to take into consideration the social and psychological context in which most rapes occur, including the non-sexual motivations of many rapists, the prevalence of rape by powerful men with access to willing partners, the fact that women of reproductive age represent only a small proportion of all rape victims, and more (Lloyd 2001). These factors suggest that rape may not be glossed as a single adaptive trait, and by ignoring this context, the view's proponents went on to defend an implausible analysis of the causes of rape and a correspondingly untenable recommendation for rape-prevention (ibid). The continuist approach risks doing something similar for "suicide" by emphasizing superficial similarities while ignoring the etiology. Anthropology and ethology have long recognized that valid classification of behavior types into "ethnograms" or "ethograms," respectively, requires a grasp of the causes and social contexts of classes of actions, as these determine their significance and meaning (Andrews 2014). A focus on surface-level features alone is liable to misclassify behavioral types, for example, misunderstanding the Italian gesture for "hello" as the American one for "goodbye" or the bared-teeth threat signal of a chimpanzee for a welcoming smile. In short, by assuming that actions can be parsed without reference to intentions, social-ecological context, or evolutionary history, the continuist approach risks producing not only heterogeneous, but arbitrary groupings that cannot serve the explanatory goals of science.

Last, by rejecting intention in suicide-classification, the continuist account threatens to frustrate ethical analysis. In biomedical ethics, for example, the permissibility of assisted suicide turns largely on the matter of autonomous consent by the patient, which presupposes the ability to understand and form intentions on the basis of this understanding. While it may be notoriously difficult to demonstrate intent, it is not impossible, and without it we lose the ability to draw many of the critical moral distinctions on which our social and legal practices are founded. Nor does the continuist view add much to the ethical analysis of self-destructive animal behaviors, as animals who engage in sustained self-injury are likely driven to such behavior by conditions that produce great suffering, and this suffering is what matters morally. By contrast, if animals were capable of suicide in the intentional sense - that is, if they were capable of forming the belief that their life was no longer worth living - this would matter very much for ethical analysis. ${ }^{2}$ This possibility would prompt the question of whether the animal was able to consent to assisted suicide and, if so, under what circumstances we would be obligated to offer such aid.

In fairness, the continuist approach does not pretend to offer a unifying explanation of the variety of self-annihilative acts it embraces. However, this raises the question of just what the reclassification is meant to accomplish. I have suggested that it cannot serve as guidance to

\footnotetext{
${ }^{2}$ See Glymour's (2017) discussion.
} 
biologists and psychologists who wish to better understand the origins of suicide, nor can it improve ethical analysis of suicide in humans or nonhuman animals. Rather than adopt an approach that aims at a broad descriptive base, a more promising and equally naturalistic approach might seek the social and ecological causes of those psychological dispositions that lead humans and perhaps a few other animal species to seek self-annihilation.

\section{References}

Andrews, K. (2014). The animal mind: An introduction to the philosophy of animal cognition. Routledge.

Davidson, D. W., Salim, K. A., \& Billen, J. (2012). Histology of structures used in territorial combat by Borneo's 'exploding ants'. Acta Zoologica, 93(4), 487-491.

Glymour, C. (2017). On assisted suicide. Animal Sentience 20(2).

Legros, C., Martin-Eauclaire, M. F., \& Cattaert, D. (1998). The myth of scorpion suicide: Are scorpions insensitive to their own venom? Journal of Experimental Biology, 201(18), 26252636.

Lloyd, E. A. (2001). Science gone astray: Evolution and rape. Michigan Law Review, 1536-1559. Peña-Guzmán, D. M. (2017). Can nonhuman animals commit suicide? Animal Sentience 20(1).

Preti, A. (2018). Animal suicide: Evolutionary continuity or anthropomorphism? Animal Sentience 20(10).

Thornhill, R., \& Palmer, C. T. (2001). A natural history of rape: Biological bases of sexual coercion. MIT Press. 